\title{
Active pulmonary tuberculosis and latent tuberculosis infection among homeless people in Seoul, South Korea: a cross-sectional study
}

\author{
Chang-Hoon Lee ${ }^{1,2}$, Yun-Jeong Jeong ${ }^{2,3}$, Eun Young Heo ${ }^{1}$, Jong Sun Park', Ji Sun Lee ${ }^{2}$, Byoung Jun Lee ${ }^{2,5}$, \\ Young Sik Park ${ }^{2}$, Eun Hee Song ${ }^{2}$, Yun Jung Yang ${ }^{2}$, Young Soo Cho ${ }^{6}$, En-hi Cho ${ }^{7}$, Kyoung-in Na', Eun-Jeong Oh', \\ Jin-beom Lee ${ }^{8}$, Soo-Yeon $\mathrm{Oh}^{8}$, HeeJin Kim ${ }^{8}$, Chang Min Park ${ }^{9}$ and Jae-Joon Yim² ${ }^{2 *}$
}

\begin{abstract}
Background: The aim of this study was to determine the prevalence rate of latent TB infection (LTBI) and active TB among homeless in Seoul metropolitan city, South Korea, and to compare the TB burden among homeless people with that of a control group.

Methods: The homeless participants were recruited from five sites between October 30, 2009 and April 12, 2010. LTBI was diagnosed through the QuantiFERON(R) TB Gold In-Tube(QFT-GIT) assay and a tuberculin skin test(TST) and, and active PTB was diagnosed based on chest radiography.
\end{abstract}

Results: Among 313 participants, the prevalence of LTBI was 75.9\% (95\% Cl, 71.1-80.8\%) and 79.8\% (95\% Cl, 74.9-84.7\%) based on a QFT-GIT assay and the TST, respectively, and that of active PTB was 5.8\% (95\% Cl, 3.2-8.3\%). The prevalence of LTBI among homeless participants was about five times higher than controls. Also, the age-specific prevalence rate ratio of active PTB was as high as 24.86 .

Conclusions: The prevalence rate of LTBI as well as active PTB among homeless people was much higher than that of the general population in South Korea. Thus, adequate strategies to reduce the TB burden among homeless people are needed.

Keywords: Tuberculosis, X-rays, Latent-TB infection (LTBI), Prevalence, Active pulmonary TB (PTB), Homeless

\section{Background}

Among infectious diseases, tuberculosis (TB) is the leading cause of mortality and morbidity worldwide, with 9.4 million incident cases and 1.7 million deaths in 2009. Most $\mathrm{TB}$ cases occur in developing countries [1]. In industrialized countries, TB is decreasing and the majority of TB cases occur in minority groups, including migrants, refugees, and itinerant people [2].

Homeless people are also at high risk for TB because of poor nutrition, alcohol consumption, and tobacco smoking [3]. Their unsafe housing conditions where TB organisms may be spread through insufficient air exchange also contributes on the occurrence of $\mathrm{TB}$ [4]. In many

\footnotetext{
* Correspondence: yimjj@snu.ac.kr

${ }^{2}$ Division of Pulmonary and Critical Care Medicine, Department of Internal Medicine, Seoul National University College of Medicine, 103 Daehak-ro, Jongno-gu 110-744, Republic of Korea

Full list of author information is available at the end of the article
}

industrialised countries, TB rates among the homeless can be up to 20 times higher than in the general population [2]. TB disease in homeless people is especially problematic because it may be highly contagious and can presents as advanced disease with poor outcomes [5]. Studies suggest that the majority of urban homeless $\mathrm{TB}$ cases are attributable to ongoing transmission of TB in developing countries, and recommendations call for tailored programs to address TB in these high-risk groups [6]. However, although several studies [5,7-10] have reported the prevalence rate of $\mathrm{TB}$ among homeless people, prior studies rarely compared the prevalence rates of both active and latent TB infection among homeless people to that of a control group or the general population. Rather, there is a report showing no statistically significant difference in pulmonary TB between homeless people and general population [11]. Additionally, there is no report on the burden and impact of TB in homeless people in

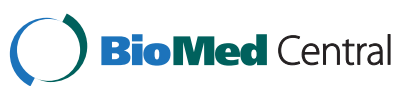


South Korea, a middle-income country and a region with an intermediate TB burden [1].

The aim of this study was to explore the prevalence rate of latent TB infection (LTBI) and active TB among homeless in Seoul metropolitan city, South Korea, and to compare the TB burden among homeless people with that of a control group.

\section{Methods}

\section{Study population}

Participants were recruited in Seoul, South Korea, between October 30, 2009 and April 12, 2010 by community outreach or by visits to homeless shelters at two streets adjacent to major railroad stations in Seoul (Seoul Station [site A] and Yeongdeungpo Station [site B]) where homeless people congregate. Three homeless shelters, sites C, D and E, were also randomly selected and visited by us. Monthly average number of homeless was $140-200$ in site A, 60-100 in site $\mathrm{B}$, and approximate total of 400 in site $\mathrm{C}, \mathrm{D}$ and $\mathrm{E}$.

Persons were eligible to participate if they were at least 20 years of age and if they provided written informed consent. Sample size was calculated as 384 by using the following formula [12]: $\mathrm{n}=(1.96)^{2} \mathrm{p}(1-\mathrm{p}) / \mathrm{d}^{2}$, where $\mathrm{n}=$ sample size, $1.96=\mathrm{Z}$ statistic for $95 \%$ confidence, $\mathrm{p}=$ expected prevalence rate $=0.5, \mathrm{~d}=$ precision $=0.05$. To facilitate enrollment, vouchers valued at about 10 US dollars were provided on second visits. This research was funded by Korea Centers for Disease Control and Prevention (2009-E31001-00).

\section{Study protocols}

After giving informed consent, each participant was interviewed using a questionnaire about demographics, previous history of $\mathrm{TB}$, smoking status, and respiratory symptoms. Height and weight were measured, and the presence of scars from bacille Calmette-Guerin (BCG) vaccination was confirmed. Also, chest radiographs (posterior-anterior) were viewed, and an interferon $-\gamma$ (IFN- $\gamma$ release assay (IGRA), QuantiFERON ${ }^{\circ}$ TB Gold In-Tube (QFT-GIT; Celletis Ltd., Victoria, Australia) and a tuberculin skin test
(TST) were conducted. This study was reviewed and approved by the Institutional Review Board of Seoul National University Hospital.

\section{Interferon- $\gamma$ release assay}

The QuantiFERON-TB Gold In-Tube (QFT-GIT) assay was performed according to the manufacturer's instructions. The plasma concentration of IFN- $\gamma$ was measured by enzyme-linked immunosorbent assay (ELISA), and the technician who performed the tests was blind to the clinical and radiographic information of the participants. Test results were interpreted as negative, indeterminate, or positive (cutoff, $0.35 \mathrm{IU} / \mathrm{mL}$ ) using the manufacturer's software [13]. Participants with indeterminate IGRA results were excluded from further analysis.

\section{Tuberculin skin test}

After collection of blood samples for the QFT-GIT assay, the TST was performed on the volar side of the forearm according to the Mantoux method using a 2-TU dose of purified protein derivative RT23 (Statens Serum Institut, Copenhagen, Denmark), and induration was measured in millimetres after $48-72 \mathrm{~h}$ using the ballpoint pen method [14]. The investigator who performed the TST was blind to the IGRA results as well as to the clinical and radiographic information of the participants. We defined a positive test as an induration of $\geq 10 \mathrm{~mm}$ [15].

\section{Interpretation of chest radiographs}

Radiographic diagnoses of active pulmonary and old healed TB were made based on previously published criteria [16] by two independent readers, including one board-certified radiologist. If the results from two were different, the final decision was made by discussion. Lesions including a cavity, a "tree-in-bud" appearance, or multiple noncalcified poorly circumscribed nodules without cavity were classified as active pulmonary TB. Lesions appearing mainly as calcified nodules or fibrotic bands in the upper lobe were classified as old healed TB.

Table 1 Demographic and clinical characteristics of homeless participants

\begin{tabular}{lcccccc}
\hline & Total & Site A & Site B & Site C & Site D & Site E \\
\hline Number & $\mathbf{3 1 3}$ & 54 & 59 & 71 & 46 & 83 \\
Male (\%) & $309(98.7 \%)$ & $53(98.1 \%)$ & $56(94.9 \%)$ & $71(100 \%)$ & $46(100 \%)$ & $83(100 \%)$ \\
Age (years), median (range) & $52(25-86)$ & $51(25-70)$ & $49(32-73)$ & $48(30-63)$ & $50.5(28-63)$ & $58(29-86)$ \\
Body mass index (kg/m $\mathbf{m}^{2}$ ), median (range) & $23.0(15.8-35.8)$ & $25.6(17.0-30.8)$ & $23.6(15.8-35.8)$ & $23.2(17.4-35.3)$ & $22.5(17.4-32.8)$ & $22.6(17.0-31.2)$ \\
Sputum production & $88(28.1 \%)$ & $\underline{18(33.3 \%)}$ & $\underline{23(39.0 \%)}$ & $\underline{17(23.9 \%)}$ & $\underline{13(28.3 \%)}$ & $\underline{17(20.5 \%)}$ \\
History of previous TB & $52 / 306(17.0 \%)$ & $12 / 53(22.6 \%)$ & $8(13.6 \%)$ & $9 / 68(13.2 \%)$ & $8 / 45(17.8 \%)$ & $15 / 81(18.51 \%)$ \\
Current or ex- smoker & $259 / 309(83.8 \%)$ & $42 / 53(79.2 \%)$ & $48 / 56(81.4 \%)$ & $64(90.1 \%)$ & $37(80.4 \%)$ & $68(81.9 \%)$ \\
Presence of BCG scar & $203 / 295(68.8 \%)$ & $29 / 37(78.4 \%)$ & $50 / 58(86.2 \%)$ & $46(64.8 \%)$ & $43(93.5 \%)$ & $35(42.2 \%)$ \\
Diabetes & $52 / 304(17.1 \%)$ & $12 / 50(24.0 \%)$ & $17 / 57(29.8 \%)$ & $4(5.6 \%)$ & $5(10.9 \%)$ & $14 / 80(17.5 \%)$ \\
\hline
\end{tabular}


Table 2 Prevalence rate of active pulmonary TB and lesions suggesting old healed TB based on CXR

\begin{tabular}{|c|c|c|c|c|c|c|}
\hline & Total & Site A & Site B & Site $C$ & Site D & Site $\mathrm{E}$ \\
\hline Number of participants & 313 & 54 & 59 & 71 & 46 & 83 \\
\hline Normal & $251(80.2 \%)$ & $44(81.5 \%)$ & $47(79.7 \%)$ & $57(80.3 \%)$ & $36(78.3 \%)$ & $67(80.7 \%)$ \\
\hline Active pulmonary TB & $18(5.8 \%)^{*}$ & $4(7.4 \%)$ & $1(1.7 \%)$ & $3(4.2 \%)$ & $3(6.5 \%)$ & $7(8.4 \%)$ \\
\hline Old healed TB & $35(11.2 \%)$ & $4(7.4 \%)$ & $9(15.3 \%)$ & $9(12.7 \%)$ & $5(10.9 \%)$ & $8(9.6 \%)$ \\
\hline Fibrotic scar & 20 & 2 & 7 & 6 & 1 & 4 \\
\hline Calcified nodule & 17 & 3 & 3 & 6 & 2 & 3 \\
\hline Significant pleural thickening & 14 & 0 & 4 & 4 & 3 & 3 \\
\hline Other abnormalities & $11(3.5 \%)$ & $2(3.7 \%)$ & $3(5.1 \%)$ & $3(4.2 \%)$ & $2(4.3 \%)$ & $1(1.2 \%)$ \\
\hline
\end{tabular}

* $95 \% \mathrm{Cl}, 3.2-8.3 \%$.

Comparison with general population of the prevalence of active pulmonary $\mathrm{TB}$, and with age, sex, and the presence of old healed lesions on chest radiograph-matched controls of the prevalence of LTBI

The prevalence rate of active pulmonary TB in homeless participants was compared with that of the population included in 2010 Korea National Health and Nutrition Examination Survey (KNHANES) by using an ageadjusted prevalence rate ratio. KNHANES used a stratified, multi-stage, clustered, probability sampling method based on the 2000 Korean Population Census administered by the National Statistical Office of Korea to select a representative sample of Korean people aged 18 years or over [17]. Presence of active pulmonary TB was decided based on chest radiographs. Interpretation of chest radiographs was performed in an identical manner described above.

We classified participants into age groups (20-29, 30-39, $40-49,50-59,60-69,70+)$, and the age-adjusted prevalence-rate ratio was calculated as follows:

Age - adjusted prevalence rate ratio

$\begin{aligned}= & \sum(\text { the observed number in each age groups }) / \\ & \sum(\text { the expected number in each age groups })\end{aligned}$
The expected numbers of active TB individuals were extrapolated from the prevalence rate of each age group in the 2010 Korea National Health and Nutrition Examination Survey.

Meanwhile, positive rates of the QFT-GIT assay and the TST were compared with controls from a Seoul National University cohort. The 'Seoul National University cohort' consists of prospectively enrolled 319 (non-homeless) participants with or without radiographic lesions suggesting old-healed TB. The detail of the cohort was described in another article [18]. From this cohort, we randomly selected age, sex, and the presence of old healed TB on chest radiograph, could find 67 pairs matching. QFTGIT and TST were conducted in a same manner. Conditional logistic regression analyses were performed to calculate the odds ratio (OR) of positive rates of the QFT-GIT assay and the TST in homeless participants compared with those in matched controls.

\section{Results}

Demographic and clinical characteristics of participants A total of 313 participants with a median age of 52 years were recruited from five sites $(54,59,71,46$ and 83 from sites A, B, C, D and E, respectively); 309 of those participants $(98.7 \%)$ were male. Fifty-two $(17.0 \%)$ had a history

Table 3 Comparison of prevalence rate of active pulmonary TB between samples from general male and homeless male populations between 2009 and 2010 using age-specific prevalence rate ratio (PR)

\begin{tabular}{|c|c|c|c|c|c|c|c|c|c|}
\hline \multirow[b]{2}{*}{$\begin{array}{l}\text { Age } \\
\text { group }\end{array}$} & \multicolumn{3}{|c|}{ Samples from general population } & \multicolumn{3}{|c|}{ Homeless people } & \multirow[t]{2}{*}{ PR } & \multirow{2}{*}{$\begin{array}{l}95 \% \\
\text { Low }\end{array}$} & \multirow{2}{*}{$\begin{array}{l}95 \% \\
\text { High }\end{array}$} \\
\hline & $\begin{array}{l}\text { Number } \\
\text { of samples }\end{array}$ & $\begin{array}{c}\text { Number of } \\
\text { active TB cases }\end{array}$ & $\begin{array}{l}\text { Active TB prevalence } \\
\text { rate }(/ 1,000)\end{array}$ & $\begin{array}{l}\text { Number } \\
\text { of samples }\end{array}$ & $\begin{array}{l}\text { Number of active } \\
\text { TB cases (observed) }\end{array}$ & $\begin{array}{l}\text { Number of active } \\
\text { TB cases (expected) }\end{array}$ & & & \\
\hline $20-29$ & 234 & 2 & 8.55 & 4 & 1 & 0.034 & 29.25 & 0.38 & 162.74 \\
\hline 30-39 & 332 & 0 & 0.00 & 33 & 0 & 0.000 & NA & NA & NA \\
\hline $40-49$ & 350 & 1 & 2.86 & 90 & 5 & 0.257 & 19.44 & 6.27 & 45.38 \\
\hline $50-59$ & 303 & 0 & 0.00 & 103 & 6 & 0.000 & NA & NA & NA \\
\hline $60-69$ & 313 & 0 & 0.00 & 41 & 2 & 0.000 & NA & NA & NA \\
\hline $70+$ & 264 & 1 & 3.79 & 18 & 2 & 0.068 & 29.33 & 3.29 & 105.91 \\
\hline Total & 1,796 & 4 & 2.23 & 289 & 16 & 0.644 & 24.86 & 14.20 & 40.37 \\
\hline
\end{tabular}


Table 4 Risk factors of active pulmonary tuberculosis among homeless participants (multivariable logistic regression analysis)

\begin{tabular}{lccc}
\hline Variables & Adjusted OR & $\mathbf{9 5 \%} \mathrm{Cl}$ & $\boldsymbol{P}$-value \\
\hline Age & 1.02 & $0.97-1.09$ & 0.427 \\
History of previous TB & 15.88 & $4.42-57.07$ & $<0.001$ \\
BMI & & & \\
$\quad \geq 18.5$ & 1 & - & - \\
$\quad<18.5$ & 7.60 & $1.37-42.24$ & 0.020 \\
Presence of BCG scar & 2.91 & $0.68-12.48$ & 0.151 \\
Presence of diabetes & 0.35 & $0.04-3.05$ & 0.342 \\
\hline
\end{tabular}

of previous TB, and BCG scars were present among 203 participants (68.8\%) (Table 1).

Prevalence rate of active pulmonary TB based on CXR

A total of 63 (20.2\%) participants had abnormal lesions in chest radiographs. Lesions suggesting active pulmonary TB were identified in 18 (5.8\%, 95\% CI, 3.2-8.3\%) participants. Abnormalities suggesting old healed TB were found in 35 (11.2\%) participants (Table 2). There was no significant difference in the prevalence rate of active TB among sites $(\mathrm{p}=0.446)$.

The prevalence rate of active TB among homeless participants was much higher than that in general population. The age-adjusted prevalence rate ratio in the homeless male group was 24.86 (95\% confidence interval; 14.20-40.37) (Table 3). Risk factors for active pulmonary TB were a history of previous TB (adjusted odds ratio [aOR], 15.88; 95\% confidence interval [95\% CI], 4.42-57.07) and lower BMI (aOR, 7.60; 95\% CI, 1.37-42.24) (Table 4).

Prevalence rate of latent TB infection among participants without active pulmonary TB

The number of participants without active pulmonary TB was 295. The results of TST were missing in seven participants. QFT-GIT assay results were positive in 224 (75.9\%, 95\% CI, 71.1-80.8\%) participants, and TST results were positive in 206 out of 258 (79.8\%, 95\% CI, 74.9-84.7\%) participants. Positive rates did not differ among study sites (Table 5). Positive rates of both tests were not affected by BCG status (Table 6).

We could match 67 pairs from the present study and Seoul National University cohort study as described above. Positive rates of the QFT-GIT assay and the
Table 6 Prevalence rate of TB infection in homeless people stratified by the status of BCG vaccination

\begin{tabular}{|c|c|c|c|c|c|}
\hline & & $\begin{array}{c}\text { Positive } \\
\text { rate }\end{array}$ & $\begin{array}{l}95 \% \\
\text { Low }\end{array}$ & $\begin{array}{l}95 \% \\
\text { High }\end{array}$ & $P$-value \\
\hline Positive QFT-GIT & & & & & 0.118 \\
\hline BCG scar negative & $73 / 88$ & $83.0 \%$ & 75.1 & 90.8 & \\
\hline BCG scar positive & $137 / 190$ & $72.1 \%$ & 65.7 & 78.5 & \\
\hline BCG scar unknown* & $14 / 17$ & $82.4 \%$ & 64.2 & 100.5 & \\
\hline Total & $224 / 295$ & $75.9 \%$ & 71.1 & 80.8 & \\
\hline Positive TST & & & & & 0.156 \\
\hline BCG scar negative & $62 / 83$ & $74.7 \%$ & 65.3 & 84.1 & \\
\hline BCG scar positive & $144 / 175$ & $82.3 \%$ & 76.6 & 87.9 & \\
\hline Total & $206 / 258$ & $79.8 \%$ & 74.9 & 84.7 & \\
\hline
\end{tabular}

*Missing or refused to be evaluated.

TST were much higher among participants compared with those controls matched for age, sex, and presence of old-healed TB lesions on CXR (QFT-GIT; 91.0\% vs. 74.6\%, OR, 4.67; 95\% CI, $1.34-16.2$ and TST; $77.4 \%$ vs. 49.1\%, OR, 6.0; 95\% CI, 1.8-20.4).

\section{Discussion}

Through this cross-sectional study that focuses on homeless people, we determined that the prevalence of radiographic active pulmonary $\mathrm{TB}$ was $5.8 \%$. In addition, prevalence of LTBI was $75.9 \%$ based on a QFT-GIT assay and $79.8 \%$ based on a TST. The age-adjusted prevalence rate ratio of active TB in males was as high as 24.86. Also, the prevalence of LTBI among homeless participants was about five times higher when compared with controls matched for age, gender, and presence of old healed TB lesions on CXR.

The prevalence of active TB as well as LTBI in our study was higher than that reported in New York in the US (31\% of LTBI) [10] and in the Airin district in Japan (1.5\% and $50.6 \%$ rate of active TB and LTBI, respectively) [9]. The higher rate of active TB and LTBI among homeless people in Seoul reflects the higher prevalence of active TB in South Korea (115 per 100000 persons) compared with the US (4.7 per 100000 persons) and Japan (27 per 100000 persons) in 2009 [1].

Development of TB disease is a two-step process: infection by transmission and progression to active disease. The risk of infection is dependent on exogenous factors. The intimacy and duration of contact with active TB cases,

Table 5 Prevalence rate of TB infection in homeless people

\begin{tabular}{|c|c|c|c|c|c|c|c|}
\hline & Total & Site $\mathrm{A}$ & Site B & Site C & Site D & Site $\mathrm{E}$ & $P$-value \\
\hline QFT-GIT (+) & 224/295 (75.9\%) & $38 / 50(76.0 \%)$ & $43 / 58(74.1 \%)$ & $55 / 68(80.9 \%)$ & $35 / 43(81.4 \%)$ & $53 / 76$ (69.7\%) & 0.507 \\
\hline TST (+) & 206/258 (79.8\%) & $19 / 25(76.0 \%)$ & $39 / 46(84.8 \%)$ & $60 / 68(88.2 \%)$ & $30 / 43(69.8 \%)$ & $58 / 76$ (76.3\%) & 0.126 \\
\hline
\end{tabular}


the degree of infectiousness of the case, and the shared environment in which the contact takes place are important risk factors [19-22]. Most homeless people in our study had resided in shelters or railroad stations, where they slept in crowded environments, conditions that could enhance transmission of tuberculosis bacilli [2]. High prevalence of LTBI among homeless in our study could be understood in this context.

Meanwhile, development of active TB depends largely on endogenous factors including HIV/AIDS [7], radiographic evidence of old healed TB [20], diabetes mellitus [23], chronic renal failure [23], immunosuppressive treatment such as TNF- $\alpha$ inhibitors [24] and use of steroids [25]. In our study, being underweight, defined as a body mass index (BMI) $<18.5 \mathrm{~kg} / \mathrm{m}^{2}$, and a history of TB were independent risk factors for active pulmonary TB. Being underweight, as an indication of malnutrition, is a well-known risk factor for progression from LTBI to active disease [26]. Malnutrition is reported to attenuate human immunity against $M$. tuberculosis [27-29] Because a history of previous TB is a risk factor in addition to underweight for active pulmonary $\mathrm{TB}$ in our study, a considerable proportion of active TB among these homeless people might be reactivated TB; however, molecular comparisons of TB strains could not be performed. Although a majority of TB cases in urban homeless populations has been regarded as attributable to ongoing transmission in shelters [2], our study underscores the importance of reactivation of previous $\mathrm{TB}$ among the homeless population.

This study did have its limitations. First, the prevalence of active TB was not based on a sputum acid-fast bacillus smear and culture but on CXR. The diagnosis of active TB based on CXR could be inaccurate as well as over-sensitive [30-32] Second, the selection of six sites of homeless populations was based on random sampling and may have caused selection bias. Third, the number of participants did not reach the calculated sample size, which could make the estimation underpowered. Fourth, our study used two different control groups (people with active $\mathrm{TB}$ and people with latent $\mathrm{TB}$ ) which might result in a potential bias. Finally, possible risk factors for TB development such as the duration of, HIV/AIDS, alcohol addiction, mental illness, history of imprisonment of the participants were not evaluated thoroughly. This might have biased the estimation of LTBI prevalence rate and the results of comparisons.

\section{Conclusions}

In conclusion, the prevalence rate of LTBI as well as active pulmonary TB among homeless people was much higher than that among general population in South Korea. Thus, adequate strategies to reduce the TB burden among homeless people are needed.

\section{Competing interests}

The authors declare that they have no competing interests.

\section{Authors' contributions}

$J J Y, E Y H, J S P, B J L, Y S P, E H S, Y J Y, J B L, S Y O, Y S C, E H C, K I N$ and EJO participated in field survey and acquisition of data. CHL, YJJ, JSL, EHS, YJY, HJK, CMP and $J J Y$ participated in analysis and interpretation of data. CHL, YJJ and JJY participated in drafting the manuscript. CHL and JJY participated in revision of manuscript critically. All authors read and approved the final manuscript.

\section{Authors' information}

Co-authors: Chang-Hoon Lee, Yun-Jeong Jeong, Eun Young Heo, Jong Sun Park, Ji Sun Lee, Byoung Jun Lee, Young Sik Park, Eun Hee Song, Yun Jung Yang, Young Soo Cho, En-hi Cho, Kyoung-in Na, Eun-Jeong Oh, Jin-beom Lee, Soo-Yeon Oh, HeeJin Kim and Chang Min Park.

\section{Acknowledgement}

We thank Hyun-Jeong Lee for her kind advice and written-English support.

\section{Author details}

${ }^{1}$ Division of Pulmonary and Critical Care Medicine, Department of Internal Medicine, Seoul National University College of Medicine, Seoul Metropolitan Government-Seoul National University Boramae Medical Center, Seoul, Republic of Korea. ${ }^{2}$ Division of Pulmonary and Critical Care Medicine, Department of Internal Medicine, Seoul National University College of Medicine, 103 Daehak-ro, Jongno-gu 110-744, Republic of Korea. ${ }^{3}$ Division of Pulmonary and Critical Care Medicine, Department of Internal Medicine, Dongguk University Ilsan Medical

Center, Gyeonggi-do, Republic of Korea. ${ }^{4}$ Division of Pulmonary and Critical Care Medicine, Department of Internal Medicine, Seoul National University College of Medicine, Seoul National University Bundang Hospital, Gyeonggi-do, Republic of Korea. ${ }^{5}$ Division of Pulmonary and Critical Care Medicine, Department of Internal Medicine, Veterans Hospital, Seoul, Republic of Korea. ${ }^{6}$ Department of Tuberculosis, Seoul Metropolitan Government Seobuk Hospital, Seoul, Republic of Korea. 'Division of HIV and TB control, Korean Centers for Disease Control and Prevention, Seoul, Republic of Korea. ${ }^{8}$ Programme Cooperation Department, Korean Institute of Tuberculosis, Seoul, Republic of Korea. ${ }^{9}$ Department of Radiology, Seoul National University College of Medicine, Seoul, Republic of Korea.

Received: 5 August 2012 Accepted: 23 July 2013

Published: 5 August 2013

\section{References}

1. WHO: Global tuberculosis control: epidemiology, strategy, financing: WHO report 2010. Geneva, Switzerland: World Health Organization 2010; 2010.

2. Figueroa-Munoz Jl, Ramon-Pardo P: Tuberculosis control in vulnerable groups. Bull World Health Organ 2008, 86(9):733-735.

3. Burki T: Tackling tuberculosis in London's homeless population. Lancet 2010, 376(9758):2055-2056.

4. Hwang SW, Kiss A, Ho MM, Leung CS, Gundlapalli AV: Infectious disease exposures and contact tracing in homeless shelters. $J$ Health Care Poor Underserved 2008, 19(4):1163-1167.

5. Khan K, Rea E, McDermaid C, Stuart R, Chambers C, Wang J, Chan A, Gardam M, Jamieson F, Yang J, et al: Active tuberculosis among homeless persons, Toronto, Ontario, Canada, 1998-2007. Emerg Infect Dis 2011, 17(3):357-365.

6. Brewer TF, Heymann SJ, Krumplitsch SM, Wilson ME, Colditz GA, Fineberg $\mathrm{HV}$ : Strategies to decrease tuberculosis in us homeless populations: a computer simulation model. Jama 2001, 286(7):834-842.

7. Moss AR, Hahn JA, Tulsky JP, Daley CL, Small PM, Hopewell PC: Tuberculosis in the homeless. A prospective study. Am J Respir Crit Care Med 2000, 162(2 Pt 1):460-464.

8. Haddad MB, Wilson TW, ljaz K, Marks SM, Moore M: Tuberculosis and homelessness in the United States, 1994-2003. JAMA 2005, 293(22):2762-2766.

9. Tabuchi T, Takatorige T, Hirayama Y, Nakata N, Harihara S, Shimouchi A, Fujita K, Yoshida H, Tamura Y, Nagai T, et al: Tuberculosis infection among homeless persons and caregivers in a high-tuberculosis-prevalence area in Japan: a cross-sectional study. BMC Infect Dis 2011, 11:22.

10. McAdam JM, Bucher SJ, Brickner PW, Vincent RL, Lascher S: Latent tuberculosis and active tuberculosis disease rates among the homeless, New York, New York, USA, 1992-2006. Emerg Infect Dis 2009, 15(7):1109-1111. 
11. Beijer U, Andreasson S: Physical diseases among homeless people: gender differences and comparisons with the general population. Scand J Public Health 2009, 37(1):93-100.

12. Daniel WW: Biostatics: a foundation for analysis in the health sciences. 7th edition. New York: John Wiley \& Sons; 1999.

13. Cellestis: QuantiFERON-TB Gold In-Tube Package Insert. Vol. 2010, 2006. Cellestis Limited (Australia), Cellestis Inc. (USA) and Cellestis GmbH (Europe); 2006. http://www.cellestis.com/IRM/Company/ShowPage.aspx?CPID=1171.

14. Sokal JE: Editorial: measurement of delayed skin-test responses. $N$ Engl J Med 1975, 293(10):501-502.

15. Ryu S, Park YK, Bai GH, Kim SJ, Park SN, Kang S: 3'UTR polymorphisms in the NRAMP1 gene are associated with susceptibility to tuberculosis in Koreans. Int J Tuberc Lung Dis 2000, 4(6):577-580.

16. Graham S, Das GK, Hidvegi RJ, Hanson R, Kosiuk J, Al ZK, Menzies D: Chest radiograph abnormalities associated with tuberculosis: reproducibility and yield of active cases. Int J Tuberc Lung Dis 2002, 6(2):137-142.

17. Lee SW, Kim YS, Kim DS, Oh YM, Lee SD: The risk of obstructive lung disease by previous pulmonary tuberculosis in a country with intermediate burden of tuberculosis. J Korean Med Sci 2011, 26(2):268-273.

18. Jeong YJ, Yoon S, Koo HK, Lim HJ, Lee JS, Lee SM, Yang SC, Yoo CG, Kim YW, Han SK, et al: Positive tuberculin skin test or interferon-gamma release assay in patients with radiographic lesion suggesting old healed tuberculosis. J Korean Med Sci 2012, 27(7):761-766.

19. Shaw JB, Wynn-Williams N: Infectivity of pulmonary tuberculosis in relation to sputum status. Am Rev Tuberc 1954, 69(5):724-732.

20. Ferebee $\mathrm{SH}$ : Controlled chemoprophylaxis trials in tuberculosis. A general review. Bibl Tuberc 1970, 26:28-106.

21. Rouillon A, Perdrizet $S$, Parrot R: Transmission of tubercle bacilli: the effects of chemotherapy. Tubercle 1976, 57(4):275-299.

22. Grzybowski S, Barnett GD, Styblo K: Contacts of cases of active pulmonary tuberculosis. Bull Int Union Tuberc 1975, 50(1):90-106.

23. Pablos-Mendez A, Blustein J, Knirsch CA: The role of diabetes mellitus in the higher prevalence of tuberculosis among Hispanics. Am J Public Health 1997, 87(4):574-579.

24. Askling J, Fored CM, Brandt L, Baecklund E, Bertilsson L, Coster L, Geborek P, Jacobsson LT, Lindblad S, Lysholm J, et al: Risk and case characteristics of tuberculosis in rheumatoid arthritis associated with tumor necrosis factor antagonists in Sweden. Arthritis Rheum 2005, 52(7):1986-1992.

25. Jick SS, Lieberman ES, Rahman MU, Choi HK: Glucocorticoid use, other associated factors, and the risk of tuberculosis. Arthritis Rheum 2006, 55(1):19-26.

26. Palmer $C E$, Jablon S, Edwards $P Q$ : Tuberculosis morbidity of young men in relation to tuberculin sensitivity and body build. Am Rev Tuberc 1957, 76(4):517-539.

27. Cegielski JP, McMurray DN: The relationship between malnutrition and tuberculosis: evidence from studies in humans and experimental animals. Int J Tuberc Lung Dis 2004, 8(3):286-298.

28. Kim HJ, Lee CH, Shin S, Lee JH, Kim YW, Chung HS, Han SK, Shim YS, Kim DK: The impact of nutritional deficit on mortality of in-patients with pulmonary tuberculosis. Int J Tuberc Lung Dis 2010, 14(1):79-85.

29. Kim DK, Kim HJ, Kwon SY, Yoon HI, Lee CT, Kim YW, Chung HS, Han SK, Shim YS, Lee JH: Nutritional deficit as a negative prognostic factor in patients with miliary tuberculosis. Eur Respir J 2008, 32(4):1031-1036.

30. Balabanova Y, Coker R, Fedorin I, Zakharova S, Plavinskij S, Krukov N, Atun R, Drobniewski F: Variability in interpretation of chest radiographs among Russian clinicians and implications for screening programmes: observational study. BMJ 2005, 331(7513):379-382.

31. Schlossberg D: Acute tuberculosis. Infect Dis Clin North Am 2010, 24(1):139-146.

32. Jeon K, Koh WJ, Kwon OJ, Suh GY, Chung MP, Kim H, Lee NY, Park YK, Bai GH: Recovery rate of NTM from AFB smear-positive sputum specimens at a medical centre in South Korea. Int J Tuberc Lung Dis 2005, 9(9):1046-1051.

doi:10.1186/1471-2458-13-720

Cite this article as: Lee et al:: Active pulmonary tuberculosis and latent tuberculosis infection among homeless people in Seoul, South Korea: a cross-sectional study. BMC Public Health 2013 13:720.

\section{Submit your next manuscript to BioMed Central and take full advantage of:}

- Convenient online submission

- Thorough peer review

- No space constraints or color figure charges

- Immediate publication on acceptance

- Inclusion in PubMed, CAS, Scopus and Google Scholar

- Research which is freely available for redistribution

Submit your manuscript at www.biomedcentral.com/submit
C BioMed Central 